\title{
A FORMAÇÃO DO PEDAGOGO E O MEIO AMBIENTE: UMA REFLEXÃO SOBRE A INCLUSÃO DA EDUCAÇÃO AMBIENTAL NOS CURSOS DE GRADUAÇÃO EM PEDAGOGIA
}

Cecilia Silva Coelho ${ }^{1}$ Ivan Claudio Guedes ${ }^{2}$

Resumo: Esse artigo traz a discussão sobre o ensino de disciplinas voltadas à Educação Ambiental em cursos de formação de professores em diferentes regiões do estado de São Paulo. Apesar de existirem em diversas orientações oficiais que exigem a abordagem de temas ambientais em todos os níveis de ensino, pode-se observar que uma pequena parcela das instituições de ensino superior ofertam em sua grade curricular disciplinas relacionadas ao tema. Assim, é possível questionar as reais possibilidades de se preparar profissionais para abordar as questões ambientais em sua prática, enquanto docentes das séries inicias do ensino fundamental. Não é objeto desse trabalho discutir a qualidade dos cursos oferecidos, mas apenas a necessidade de se discutir a formação do profissional pedagogo para lidar com a temática ambiental com seus alunos, propondo o levantamento de reflexões sobre como formar cidadãos mais aptos a atuar na preservação do meio ambiente e na mitigação de impactos ambientais gerados ao longo dos tempos.

Palavras-chave: Educação Ambiental; Ensino Superior; Meio Ambiente.

\footnotetext{
${ }^{1}$ Faculdade Método de São Paulo, São Paulo, SP. E-mail: ceciliascoelho@gmail.com

2 Faculdade Progresso, São Paulo, SP. E-mail: ivanclaudioguedes@gmail.com
}

Revbea, São Paulo, V.11, № 2: 151-163, 2016.

revista brasileira educação ambiental 


\section{Introdução}

As questões ambientais vêm tomando grande destaque na mídia e ocupando vários espaços de discussão. Os veículos de informação têm demostrado mais interesse em noticiar e veicular matérias com a temática ambiental. As grandes companhias realizam propagandas sobre as mudanças que sofreram para se tornarem sustentáveis. Em muitos estabelecimentos, encontram-se recipientes adequados ao descarte dos resíduos recicláveis, entre outros. A temática ambiental esteve tão presente no final do século XX que recebeu maior atenção do sistema educacional. Os Parâmetros Curriculares Nacionais (PCN) preveem a inserção do tema "Meio Ambiente" no tratamento dessa temática enquanto tema transversal (BRASIL, 1997). Não obstante, a Política Nacional de Educação Ambiental também determinou que esse tema fosse tratado em todos os níveis de ensino, "por meio inclusive da construção de novos currículos, nos quatro níveis de ensino, que contemplem a temática ambiental' (BRASIL, 2005, p. 50), adiante, tal determinação ganhou sua regulamentação com a Resolução do Conselho Nacional de Educação 01/06 que determina a inserção de estudos teórico-práticos, investigação e reflexão crítica de forma com que propicie os conhecimentos ambientais e ecológicos nos cursos de Pedagogia (CNE, 2006).

Assim, as instituições de ensino procuraram se adequar aos referenciais curriculares e à legislação, desenvolvendo projetos e disciplinas sobre temas ambientais. A discussão ambiental se tornou, então, primordial em um processo educativo que teve como objetivo a incorporação de novos valores e práticas em relação ao meio ambiente.

Tanto o PCN quanto a Política Nacional de Educação Ambiental (BRASIL, 1997; 1999) orientam que sejam trabalhados os temas ambientais em todos os segmentos do ensino. Entende-se que, para tratar dos temas ambientais em ambiente escolar, o docente deva ser qualificado para desenvolver tal função. Diante disso, levanta-se a seguinte questão: como esses professores, responsáveis pelo trabalho com o tema Meio Ambiente, são preparados? Como ocorre a formação dos educadores que trabalharão com a educação infantil e ensino fundamental dentro da temática ambiental? As instituições de ensino superior têm oferecido aos seus cursistas alguma disciplina que discuta a temática ambiental?

Thomaz (2006) realizou um estudo no qual teve como objetivo investigar se a inserção da Educação Ambiental é mais adequada se desenvolvida de forma interdisciplinar ou disciplinar no Ensino Superior. Concluiu que há um entendimento parcial das leis e consequentemente divergências em relação à operacionalização da Educação Ambiental nessa modalidade de ensino. Encontrou como base comum a necessária formação do educador e da ambientalização curricular das instituições. $O$ autor também problematiza a questão de que faculdades e universidades são espaços privilegiados de discussão científica e desenvolvimento da Educação Ambiental. 
Ainda que as questões acima demandem um estudo mais aprofundado, é objetivo deste estudo apresentar apenas um breve diagnóstico sobre a oferta de cursos de licenciatura em Pedagogia no estado de São Paulo, que oferecem em sua grade curricular alguma disciplina que tenha como objetivo preparar tal profissional para trabalhar essa temática em sua prática docente. Pretende-se, assim, entender um pouco melhor a formação dos professores em relação à Educação Ambiental (EA); e apresentar, ainda que superficialmente, uma discussão sobre a importância de se inserir temas que contemplem as questões do meio ambiente dentro da proposta curricular das instituições de ensino superior.

Guedes e Victorino (2010, p. 93) afirmam que "o professor é o agente principal do processo de formação das novas gerações", portanto, é possível afirmar que é de suma importância que o conceito de sustentabilidade e Educação Ambiental esteja dentro das grades curriculares dos cursos de formação inicial de professores.

\section{Entendendo a Educação Ambiental}

A sociedade encontra-se em um período em que os problemas ambientais estão colocados em evidência, pela mídia, pelas autoridades (com a criação de leis, ministérios e projetos) e pela sociedade. $O$ tema sustentabilidade está "na moda", contudo, são tímidas as reais mudanças comportamentais que compõem essa sociedade. Via de regra, o que se encontram são experiências esparsas e que contrariam 0 modelo de desenvolvimento econômico vigente. A Educação Ambiental, então, tem como objetivo o "posicionamento crítico face à crise socioambiental, tendo como horizonte a transformação de hábitos e práticas sociais" (JACOBI, 2005, p 233). Assim, entende-se que é a partir do trabalho efetivo com a Educação Ambiental que o professor poderá estar plena e realmente mobilizado e instrumentalizado para a prática de ações realmente sustentáveis.

A Educação Ambiental refere-se à prática educativa voltada para as questões ambientais, considerando o respeito à vida, à diversidade, ao desenvolvimento sustentável e à melhoria da qualidade de vida das pessoas. Tem como objetivo principal a conscientização e mudança de práticas e ações desenvolvidas no meio ambiente. De acordo com a Coordenadoria de Educação Ambiental do Governo do Estado de São Paulo (SÃO PAULO, 1998, p.7), deve ser "um ato político voltado para a transformação social", com o desafio de que a EA seja crítica e inovadora nos níveis da Educação Formal e Não Formal.

Por definição da IUCN - International Union for the Conservation of Nature - em 1970, Educação Ambiental é entendida como "um processo de reconhecimento de valores e clarificação de conceitos, voltado para o desenvolvimento de habilidades e atitudes necessárias à compreensão e apreciação das inter-relações entre o homem, sua cultura e seu entorno biofísico." (DIAS, 2004, p. 98)

Revbea, São Paulo, V.11, № 2: 151-163, 2016.

revista brasileira educação ambiental 
A Organização das Nações Unidas para a Educação, a Ciência e a Cultura (UNESCO, 2005) defende que a Educação Ambiental seja uma disciplina bem estabelecida que enfatize a relação dos homens com 0 ambiente natural, as formas de conservá-lo, preservá-lo e administrar seus recursos adequadamente. Essa agência, em conjunto com o Ministério do Meio Ambiente, executa o Programa Nacional de Educação Ambiental (ProNEA), cujos objetivos são: assegurar, no âmbito educativo, a integração equilibrada das múltiplas dimensões da sustentabilidade - ambiental, social, ética, cultural, econômica, espacial e política - ao desenvolvimento do país e buscar o envolvimento e a participação social na proteção e conservação ambiental [...] a longo prazo.

PRONEA (2005, p. 33) prevê sobre a EA:

Que suas ações destinam-se a assegurar, no âmbito educativo, a interação e a integração equilibradas das múltiplas dimensões da sustentabilidade ambiental - ecológica, social, ética, cultural, econômica, espacial e política - ao desenvolvimento do país, buscando o envolvimento e a participação social na proteção, recuperação e melhoria das condições ambientais e de qualidade de vida.

Jacobi e Fernandes (2009) defendem que a EA deve ser vista como uma formação para a cidadania e tem a ver com uma nova forma de encarar a relação do homem com a natureza, baseada numa nova ética, que pressupõe valores morais diferentes dos culturalmente impetrados na sociedade e uma forma diferente de ver a relação entre mundo e os homens. Ainda nessa linha de pensamento, Reigota (2008) realizou um trabalho no qual questiona o papel da discussão sobre meio ambiente como uma ação política e propõe o desafio de formar uma nova geração de educadores ambientais que entendam os principais fundamentos da EA, a cidadania e a ética.

Tozzoni-Reis (2001, p. 42) acredita que a EA (que é uma dimensão da Educação) potencializa a atividade humana e sua relação com a natureza, "tornando-a mais plena de prática social e de ética ambiental" e conclui que deve haver uma maior reflexão sobre a formação dos educadores ambientais em formação.

Entende-se, assim, que é preciso compreender como os profissionais da educação (neste trabalho especificamente os pedagogos) podem ser instrumentalizados para atuarem de forma significativa nas mudanças das relações do homem com a natureza, a partir de uma reflexão e práticas relacionadas à essa temática - a Educação Ambiental, sobre a qual tentamos nesse capítulo apresentar um rápido resumo da sua definição e importância. 


\section{A Educação Ambiental nos cursos de formação de pedagogos}

De acordo com Veronez et al. (2009), a conscientização das pessoas para uma vida mais harmônica com a natureza passa pela educação tanto informal quanto formal, em todos os níveis de ensino. Isso significa formar cidadãos que entendam as causas e compreendam os efeitos das ações do homem sobre os ecossistemas, tendo consciência sobre suas responsabilidades em relação ao meio ambiente. Assim, o trabalho com a Educação Ambiental procura desenvolver o senso crítico para tornar possível a resolução dos problemas ambientais aos quais estamos expostos e que nos concerne.

A Lei 9.795 de 27 de abril de 1999, no seu Artigo 3o, parágrafo I, prevê que a Educação Ambiental seja promovida em todos os níveis de ensino, e mais do que isso, que é responsabilidade do Poder Público definir políticas públicas para que a dimensão ambiental seja incorporada (BRASIL, 1999). Assim, concluímos que o nível superior também deveria promover tempo e espaço para a discussão do tema. Ainda no tocante à legislação, a Resolução CNE/CP 01/2006 institui as Diretrizes Curriculares Nacionais para o curso de licenciatura em Pedagogia. Ainda que as diretrizes não imponham necessariamente a disciplina, ela aponta (dentre outros) os princípios que os cursos devem oferecer aos seus alunos. Logo no artigo $2^{\circ}$ da referida Resolução, apontam-se, no parágrafo segundo que o curso de Pedagogia deva propiciar "por meio de estudos teórico-práticos, investigação e reflexão crítica (...) a aplicação ao campo da educação, de contribuições, entre outras, de conhecimentos (...) ambiental-ecológico" (CNE, 2006). Adiante, no artigo quinto, a resolução afirma que o egresso do curso de Pedagogia deverá estar apto a "demonstrar consciência da diversidade, respeitando as diferenças de natureza ambiental-ecológica" (CNE, 2006).

A resolução citada compreende que a docência deva ser realizada a partir de uma ação educativa metódica e intencional, ou seja, neste caso, este trabalho entende que o processo de ensino e aprendizagem (sobretudo da formação do pedagogo) deve ser estruturada e sistematizada em um currículo, não deixando margem para sugerir que a educação ambiental deva ter trabalhar como tema transversal (como é na educação básica).

Raymundo e Oliveira (2007, p. 269) definem que os educadores ambientais (independentemente da formação) necessitam de investimentos pedagógicos, metodológicos, educacionais, políticos e financeiros para 0 "estabelecimento e fortalecimento de propostas concretas [...]" e, assim, poderão intervir de forma crítica "para a transformação da realidade do mundo".

Santos (2011) defende que uma nova realidade socioambiental é construída a partir de uma nova concepção de currículo, de escola e, consequentemente, da reformulação da prática docente em relação às questões socioambientais. Evidencia, ainda, a importância de o professor adotar um papel crítico e reflexivo, dentro de um contexto prático. 
Silva et al. (2006, p. 4) desenvolveram um trabalho no qual realizaram uma tentativa de inserir a Educação Ambiental na formação dos pedagogos, visando "desencadear um processo reflexivo e introspectivo de busca de uma nova ordem nas relações homem e meio", por meio de um projeto conjunto entre o curso de graduação em pedagogia e o programa de Mestrado em Educação da Universidade do Sul de Santa Catarina. Os resultados desse estudo apontam que $100 \%$ do total de participantes (estudantes da graduação) demonstraram interesse pela continuidade do projeto, e também sinalizaram que os conteúdos abordados contribuíram para a melhoria da prática pedagógica. Concluíram que o projeto aproximou os educadores da problemática ambiental e apontaram a necessidade da EA ser abordada em todos os cursos de pedagogia.

Mello, Montes e Lima (2009, p. 48) buscaram em seu estudo "propiciar novas vivências ambientais do homem com a natureza, com vistas à compreensão e tratamento ético da questão ambiental" e concluíram que os conteúdos abordados em sala de aula devem ser aplicados e adequados à realidade social. Diniz (2008) também defende em seu trabalho a importância de elaborar atividades que envolvam a participação ativa do indivíduo.

Dessa forma, destaca-se a importância de aproximar os futuros educadores (no caso, estudantes do curso de graduação em Pedagogia) da temática ambiental. Pois, se serão eles os responsáveis pela formação de indivíduos ativos na sociedade, deverão estar sensibilizados e instrumentalizados sobre a EA, para que sejam capazes de formar cidadãos responsáveis pela sua relação com o meio ambiente.

\section{Metodologia da pesquisa}

Este estudo valeu-se da pesquisa quantitativa. Para o levantamento dos dados referentes à grade curricular das instituições de ensino que oferecem o curso de Licenciatura em Pedagogia, foi utilizada a pesquisa virtual, ou seja, as informações (referentes às grades curriculares) disponibilizadas nos sites das diversas Instituições de Ensino Superior, escolhidas seguindo o critério da ordem de aparecimento no site, foram analisadas e buscou-se a possibilidade de verificar suas grades curriculares. Essa pesquisa teve início no site da Revista Guia do Estudante, publicação da Editora Abril, endereço eletrônico no qual seria possível o acesso às diversas instituições. Algumas faculdades não disponibilizam as grades curriculares para o público em geral, não sendo possível a verificação destas para comporem o banco de dados, assim, foram descartadas do estudo. Das 100 faculdades pesquisadas, apenas 60 disponibilizaram tais dados. Consideraram-se as disciplinas que apresentavam no nome as seguintes palavras-chave: educação ambiental; sustentabilidade; meio-ambiente; ecologia. Não foram analisadas as cargas horárias bem como o momento da graduação na qual são ministradas. Foram descartadas as disciplinas sobre Conteúdos e Metodologia do Ensino de Ciências Naturais e/ou Biologia, pois estas são disciplinas presentes no Ensino Fundamental e não, necessariamente, contemplam a abordagem das questões da Educação 
Ambiental. A análise dos dados consistiu em analisar as duas possibilidades oferecer ou não disciplina relacionada à Educação Ambiental; instituição localizada dentro ou fora da cidade de São Paulo (SP) para posterior comparação dos dados. Depois foram comparadas as variáveis apresentar / não apresentar disciplina pesquisada em relação a estar / não estar localizado em SP, para verificarmos se haveriam diferenças nos resultados, relacionadas à localização.

\section{Resultados e discussões}

O Gráfico 1 mostra o número (e porcentagem) de cursos de pedagogia (dentre aqueles pesquisados no site da Revista Guia do Estudante) que oferecem ou não alguma disciplina correspondente à educação ambiental. Observa-se que menos da metade das 60 instituições pesquisadas apresentam em sua grade curricular disciplinas ligadas à Educação Ambiental. Ora, se o tema está cada vez mais recorrente na mídia e no discurso das mais diversas entidades, instituições e empresas, e se há também a crença e defesa de que a sociedade deve repensar suas atitudes frente ao meio ambiente (além da clara disposição na resolução que trata das Diretrizes Curriculares Nacionais para o Curso de Graduação em Pedagogia, licenciatura, como já discutido anteriormente), porque se encontrou um número tão baixo de instituições de ensino superior que se disponibilizam a formar profissionais que têm em sua formação um mínimo de estudo sobre isso? Vale lembrar que este trabalho não tem a pretensão de discutir a carga horária e a qualidade das disciplinas oferecidas, pois dependeríamos da disponibilidade das instituições estudadas em nos fornecer informações mais detalhadas para que pudéssemos desenvolver este estudo mais aprofundado. Atentando-se simplesmente à questão "oferecer ou não" alguma matéria que contemple discussões sobre a Educação Ambiental é possível suscitar questionamentos sobre a superficialidade com que as questões ambientais estão sendo tratadas, mediante os baixos números coletados durante esta pesquisa.

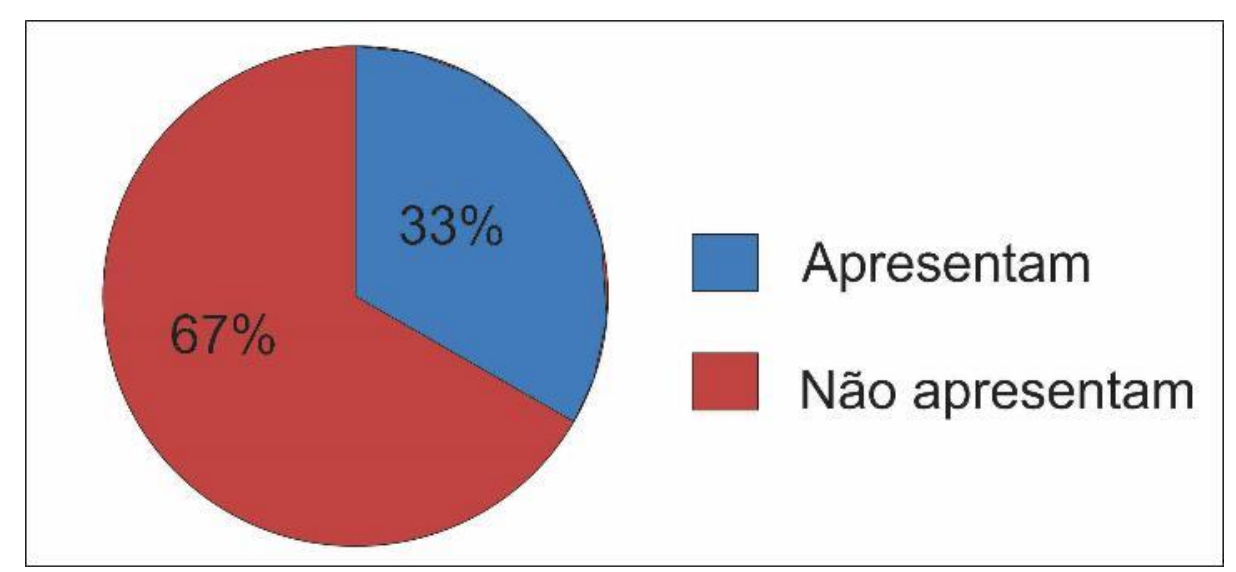

Gráfico 1: Número (e porcentagem) de cursos de pedagogia que oferecem ou não alguma disciplina correspondente à educação ambiental. Total de 60 . 
O Gráfico 2 mostra o número absoluto de instituições pesquisadas de acordo com a localização. Foram analisadas na pesquisa 25 instituições de ensino localizadas na cidade de São Paulo e 35 em diferentes pontos do Estado. É possível observar, no Gráfico 3, que das 25 instituições da capital, apenas $7(28 \%)$ estão na categoria "Oferece" disciplina relacionada à Educação Ambiental, diferentemente do demonstrado no Gráfico 4, no qual observa-se que $43 \%$ das instituições localizadas fora da cidade de São Paulo apresentam em sua grade curricular alguma disciplina que aborde o tema. Levanta-se aqui a hipótese de que a capital, apesar de ser um dos principais centros financeiros e educacionais do país, ainda não se atenta para a necessidade de iniciar um trabalho profundo e significativo de conscientização e formação dos cidadãos que aqui vivem, em relação aos cuidados com o meio ambiente, sendo que é também considerada uma das cidades que mais sofre com as questões da poluição e da degradação do meio ambiente, e assim esperava-se que houvesse um maior comprometimento com as questões ambientais e seus desdobramentos.

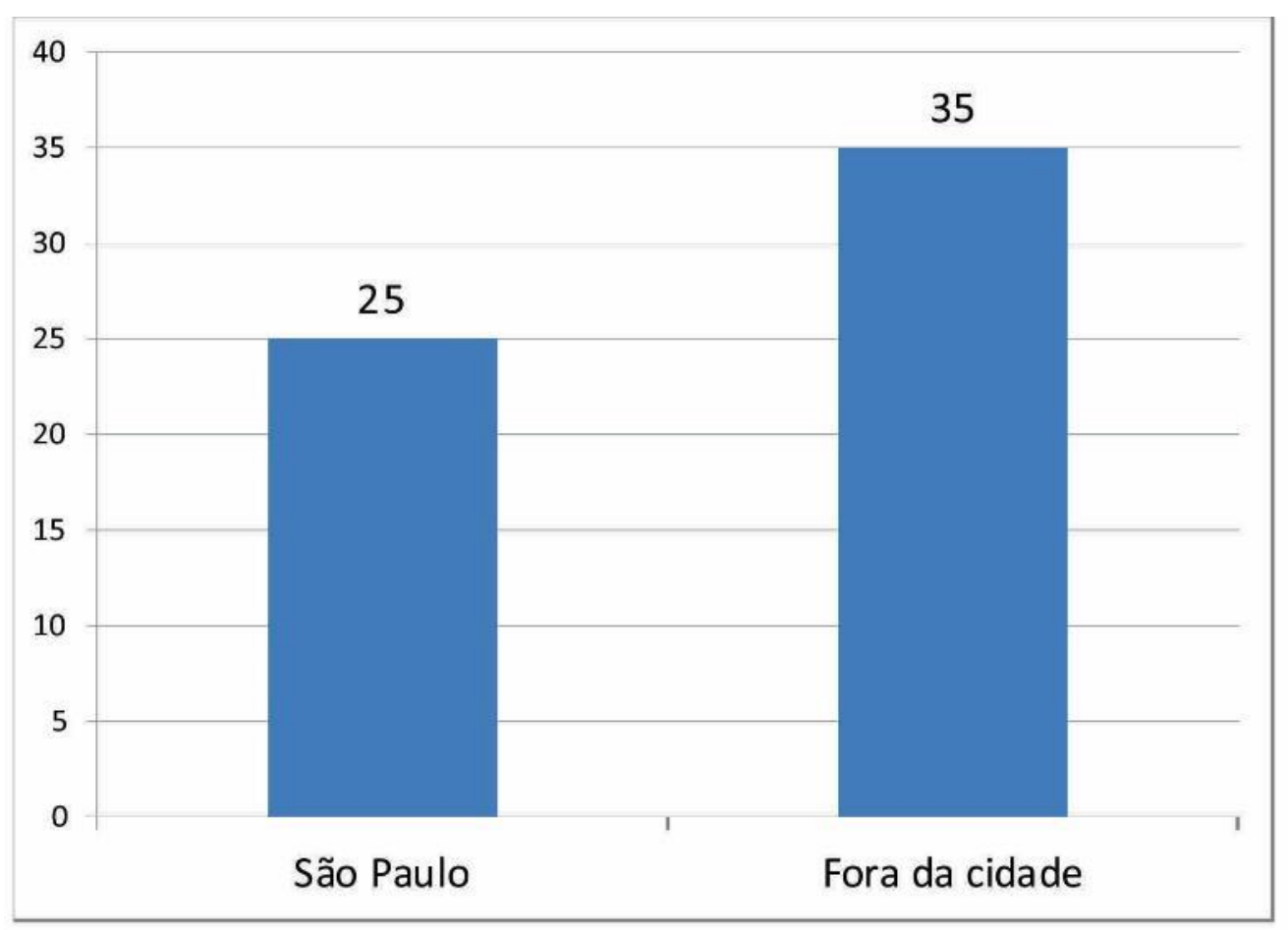

Gráfico 2: Número de instituições pesquisadas de acordo com a localização. Total de 60. 


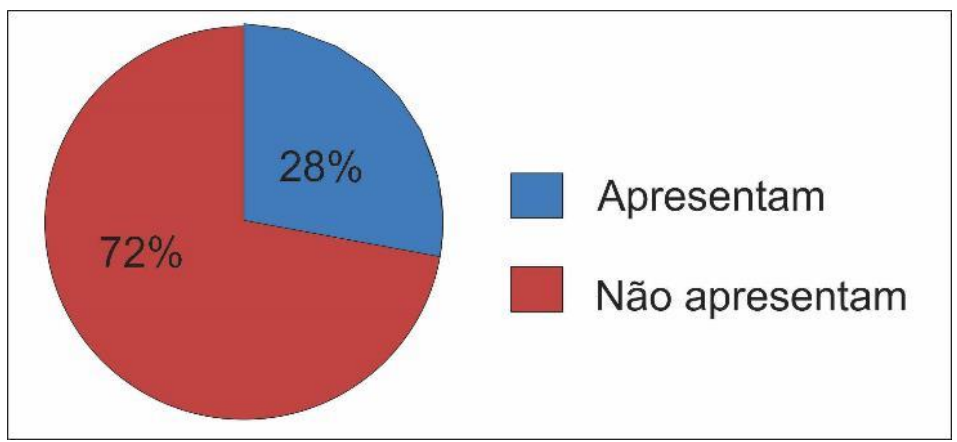

Gráfico 3: Número de instituições localizadas na cidade de SP que apresentam ou não alguma disciplina relacionada à Educação Ambiental na sua grade curricular. Total de 25.

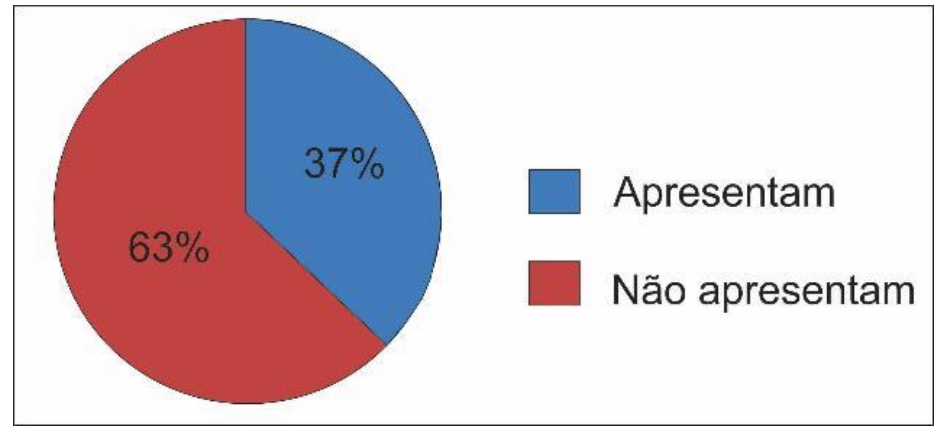

Gráfico 4: Número de instituições localizadas fora da cidade de SP que apresentam ou não alguma disciplina relacionada à Educação Ambiental em sua grade curricular. Total de 35.

O Gráfico 5 apresenta um resumo desses resultados, comparando os números absolutos entre as instituições da cidade de SP e de fora dela, em relação a apresentar ou não disciplina relacionada à Educação Ambiental em sua grade curricular. É possível observar diferenças significativas entre as instituições situadas na cidade de São Paulo e fora dela.

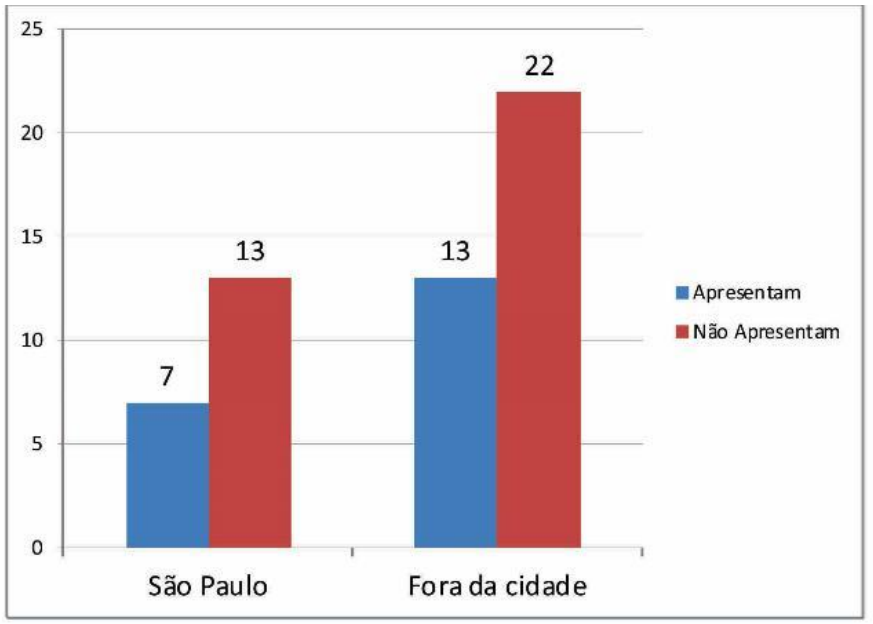

Gráfico 5: Comparativo dos números entre as instituições da cidade de SP e de fora dela, em relação a apresentar ou não disciplina relacionada à Educação Ambiental em sua grade curricular.

Revbea, São Paulo, V.11, № 2: 151-163, 2016. 
A Figura 1 apresenta a distribuição geográfica das instituições de ensino no Estado de São Paulo, para melhor visualização. Foram analisadas instituições em diferentes pontos do território paulista em diversos contextos sociais e econômicos, ainda que não estudados de forma aprofundada nesse estudo.

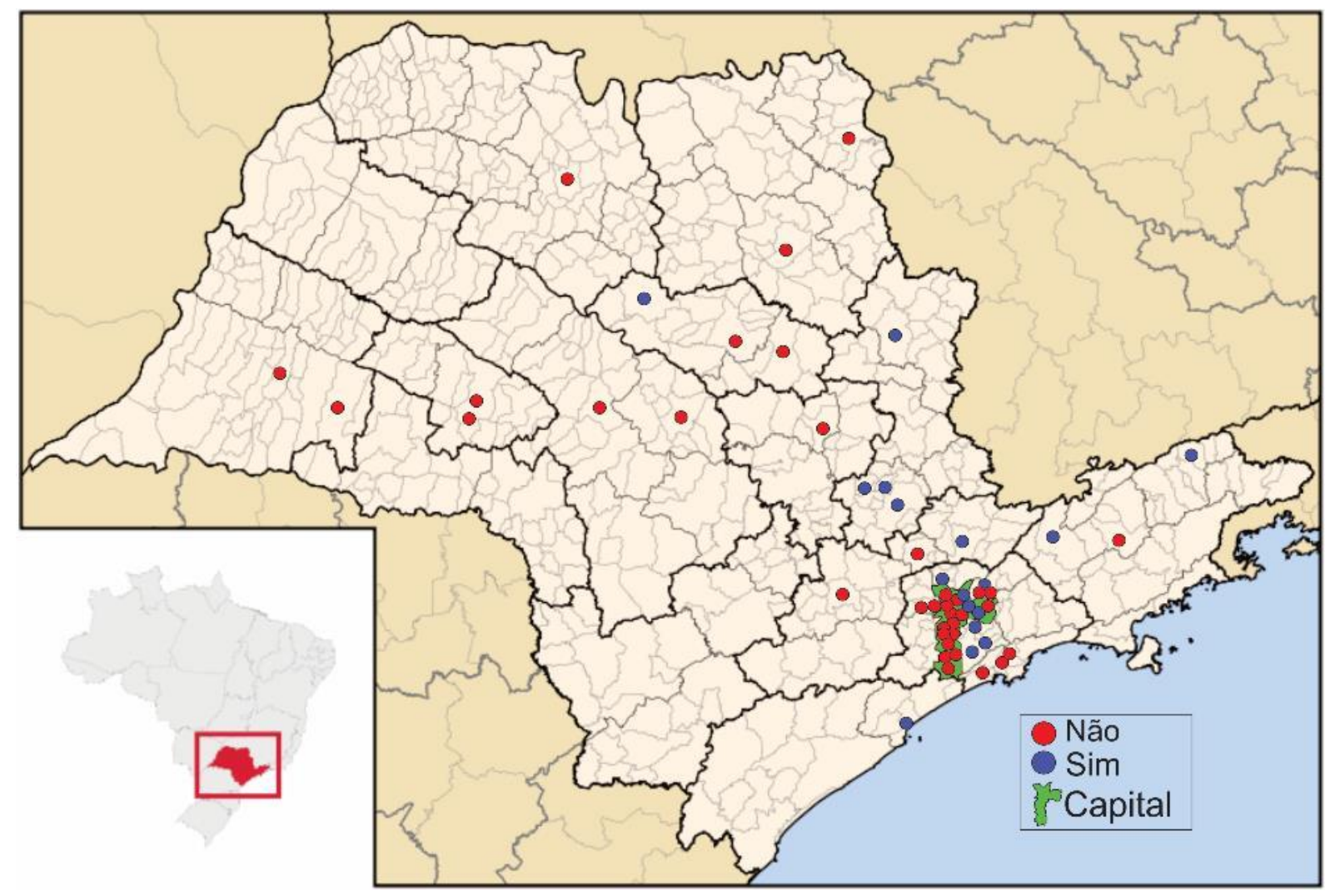

Figura 1: Distribuição geográfica das instituições de ensino no estado de São Paulo, de acordo com a variável apresentar ou não o tema meio ambiente na sua grade curricular de Licenciatura em pedagogia.

\section{Considerações finais}

Muito se fala sobre a importância da sensibilização da sociedade em relação à mudança de atitudes e competências na tentativa de contribuir para a resolução dos problemas ambientais. No entanto, pouco se atenta para a necessidade de conscientizar as pessoas por meio da educação ambiental nas escolas, uma vez que pudemos observar poucos cursos de graduação em pedagogia que abrem espaço em suas grades curriculares para a discussão sobre a EA na formação inicial dos professores, agentes ativos nesse processo de envolvimento pela busca de possíveis soluções e mudanças necessárias para a conservação e o respeito ao meio ambiente. 
A prática ambiental demanda mudanças de comportamento, e os educadores devem ser instrumentalizados para se tornarem capazes de desenvolver trabalhos significativos que envolvam o meio ambiente. Esse processo de formação do professor é paulatino, que deve envolver, nas instituições de ensino superior, toda a equipe: gestão, coordenação, docentes, discentes.

Assim como Diniz (2008), e Mello, Montes e Lima (2009), acreditamos que existe a necessidade de analisar e formular propostas para a implementação de encontros e debates que tratem da EA na formação inicial de professores, assim os educadores podem se apropriar dos conteúdos e desenvolver movimentos de reflexão e ação de inserção deste tema nas práticas pedagógicas.

Ainda, sendo a escola um local propício para a discussão de temas relativos à nossa sociedade com o objetivo de transformá-la, temos a EA a serviço da transformação de ideias e práticas mais responsáveis em relação ao meio ambiente. A EA não seria, portanto, apenas mais uma matéria no currículo obrigatório das universidades e faculdades, não é simplesmente uma carga horária a mais nos programas de formação inicial de professores. Ela é um desafio que se faz necessário para que possam ser observadas reais propostas de melhoria da qualidade de vida das pessoas, a partir da preocupação com o nosso ambiente.

Chama a atenção observar que, de quatro universidades pesquisadas que se encontram nas regiões litorâneas do estado de São Paulo - duas de Santos, uma de São Vicente, e outra de Peruíbe - apenas uma oferece a disciplina Educação Ambiental na sua grade curricular, como observado na Figura 1. Pois, em regiões tão ricas de ecossistemas (podemos citar as regiões de mangues, por exemplo), nas quais o contato com a biodiversidade é mais corriqueiro, esperava-se que esse tema fosse abordado de forma mais aprofundada e que houvesse iniciativas visíveis de inclusão do tema nas discussões realizadas nas instituições. Da mesma forma, ao refletir sobre as regiões do interior de São Paulo, por estarem mais próximas de campos, fazendas, plantações, etc., esperava-se que tivessem mais facilidade de incluir a EA nos currículos das suas universidades. No entanto, observa-se nos resultados da pesquisa que o número de instituições que oferecem em seus cursos a disciplina é também reduzido.

Podemos pensar no contrário também, pois a cidade de São Paulo, por possuir regiões urbanizadas cada vez mais densas e por enfrentar problemas tão sérios em relação ao meio ambiente, como a poluição do ar - ocasionando problemas sérios de saúde nas pessoas, da impermeabilização do solo -, causando enchentes cada vez mais recorrentes, entre outros, deveria estar mais aberta à inclusão do tema EA nas suas instituições de ensino. Se partirmos da premissa de que é desde o início da sua vida social que o indivíduo aprende a interagir com ambiente que o cerca, por que não, então, promover uma formação mais completa dos professores para que estes sejam cada vez mais conscientes e criticamente competentes, capazes de formar

revista brasileira educação ambiental 
também cidadãos prontos para o pleno exercício da cidadania, que inclui ser responsável por sua ação em relação à natureza? Independentemente do contexto em que está inserido, o cidadão deve estar ciente da sua importância na relação com o meio ambiente, esteja ele dentro de uma metrópole ou de uma cidade interiorana.

A tomada de consciência da importância da abordagem da EA nos cursos de formação inicial de professores é um processo paulatino que envolve diversas instâncias como o Governo, os estados, as universidades públicas e privadas e a sociedade como um todo. Este trabalho procurou mostrar, de forma ainda que superficial, a falta de profundidade do tema ambiental, especialmente relacionado à $E A$, e a formação dos professores e buscou mais do que respostas, suscitar questionamentos acerca das possíveis mudanças necessárias.

\section{Referências}

BRASIL. Secretaria de Educação Fundamental. Parâmetros Curriculares Nacionais: apresentação dos temas transversais, ética / Secretaria de Educação Fundamental. Brasília: MEC;SEF, 1997. 146p.

BRASIL. Programa nacional de educação ambiental - ProNEA / Ministério do Meio Ambiente, Diretoria de Educação Ambiental; Ministério da Educação. Coordenação Geral de Educação Ambiental. - 3. ed - Brasília: Ministério do Meio Ambiente, 2005. 102p.

BRASIL. Lei 9.795, de 27.04.1999. Dispõe sobre Educação Ambiental e institui a Política Nacional de Educação Ambiental, e dá outras providências. DOU 28.04.1999.

CONSELHO NACIONAL DE EDUCAÇÃO. Resolução 01, de 15.05.2006. Institui Diretrizes Curriculares Nacionais para o Curso de Graduação em Pedagogia, licenciatura. DOU, SEÇÃO 1, p. 11. 16.05.2006.

DIAS, G.F. Educação Ambiental: princípios e práticas. 9. ed. São Paulo: Gaia, 2004.

DINIZ, B. Relato de experiência: a educação ambiental na formação de professores. Rev. Simbio-Logias, v.1, n 2, Nov/2008.

GUEDES, I.C.; VICTORINO, L. A. Breve discussão sobre a sustentabilidade nos cursos de formação de educadores: construindo as bases para uma educação sustentável. Revista Brasileira de Educação Ambiental (REVBEA), v. 5, n. 1, p. 89-95, 2010.

JACOBI, P.R. Educação ambiental: o desafio da construção de um pensamento crítico, complexo e reflexivo. Educação e Pesquisa, São Paulo, v. 31, n. 2, p. 233-250, maio/ago. 2005. 
JACOBI, P.R.; FERNANDES, M. Educação e sustentabilidade: caminhos e práticas para a educação transformadora. São Paulo: Evoluir Cultural, 2009.

MELLO, A.S.; MONTES, S.R.; LIMA, L. Educação Ambiental em curso de formação continuada para docentes do ensino básico - Uberlândia (MG). Em extensão, Uberlândia, v. 8, n. 1, p. 48 - 59, jan./jul. 2009

MINISTÉRIO DO MEIO AMBIENTE, Diretoria de Educação Ambiental; Ministério da Educação. Coordenação Geral de Educação Ambiental. Programa nacional de educação ambiental - ProNEA / 3. ed. Brasília: Ministério do Meio Ambiente, 2005. 102p.:

RAYMUNDO, M.H.A.; OLIVEIRA, V.G. Profissional-Educador-Ambiental: a utopia construída. In: FERRARO JUNIOR, L.A. Encontros e Caminhos: formação de educadores (as) ambientais e coletivos educadores. MMA, Departamento de Educação Ambiental, 2007. v. 2, 352p.

REIGOTA, M.A.S. Cidadania e Educação Ambiental. Psicologia e Sociedade, São Paulo, v. 20, n. esp, p. 61-69, 2008.

SÃO PAULO. Governo do Estado de São Paulo, Secretaria de Meio Ambiente, Coordenadoria de Educação Ambiental. Educação, Meio Ambiente e Cidadania: Reflexões e Experiências. 1998 - 121 páginas.

SANTOS, V. M. N. Educar no ambiente: construção do olhar geocientífico e cidadania. São Paulo: Annablume, 2011. (Coleção Cidadania e Meio Ambiente).

SILVA et al. A educação ambiental na formação do pedagogo: uma experiência integrada na UNISUL - Tubarão (SC). UNIrevista, v. 1, n. 2, abril. 2006.

THOMAZ, C.E. Educação Ambiental na formação inicial de professores. 2006. Dissertação (Mestrado em Educação). Pontifícia Universidade Católica Campinas, $107 \mathrm{p}$.

TOZZONI-REIS, M.F.C. Educação Ambiental: Referências teóricas no ensino superior. Interface - Comunic, Saúde, Educ., v. 5, n. 9, p.33-50, 2001. Disponível em: <http://dx.doi.org/10.1590/S1414-32832001000200003>. Acesso em: 31 jul. 2012.

UNESCO Década da Educação das Nações Unidas para um Desenvolvimento Sustentável, 2005-2014: documento final do esquema internacional de implementação. Brasília: UNESCO, 2005. 120p.

VERONEZ W. M. et al. A utilização do terrário para conscientização ambiental de estudantes do ensino básico. R.B.E.C.T, v. 2, n. 3, set.dez. 2009. 